\title{
Lysozyme Enhances Renal Excretion of Advanced Glycation Endproducts In Vivo and Suppresses Adverse AGE-mediated Cellular Effects In Vitro: A Potential AGE Sequestration Therapy for Diabetic Nephropathy?
}

\author{
Feng Zheng, Weijing Cai, Tomoko Mitsuhashi, and Helen Vlassara \\ Division of Experimental Diabetes and Aging, Mount Sinai School of Medicine, New York, NY \\ Contributed by R. Bucala. Accepted September 21, 2001
}

\begin{abstract}
Background: Lysozyme (LZ), a host-defense protein, contains an 18 amino-acid domain with high affinity binding for sugar-derived proteins or lipids, called advanced glycation endproducts (AGE), that are implicated in diabetesand age-dependent complications (DC).

Materials and Methods: A) The effects of LZ on AGEremoval were tested in vivo. $\mathrm{LZ}$ was injected $(200 \mathrm{ug} /$ day, i.p., $\times 2$ weeks) in non-obese diabetic (NOD), $d b / d b(+/+)$ mice, and non-diabetic, AGE-infused Sprague-Dawley rats. B) LZ: AGE interactions with macrophage-like T1B-183 cells (Mf) and mesangial cells (MC) were tested in vitro.

Results: A) In NOD mice, LZ reduced the elevated basal serum AGE (sAGE) $(p<0.05)$, enhanced urinary AGE (uAGE) excretion by $\sim 2$-fold ( $p<0.01)$, while it reduced albuminuria (UA), $\mathrm{p}<0.005$. In $d b / d b$ mice, LZ infusion
\end{abstract}

also reduced the elevated sAGE $(p<0.05)$, doubled uAGE excretion $(p<0.05)$, and decreased UA $(p<0.01)$. In addition, LZ maintained normal sAGE in normal rats infused with AGE-BSA, as it doubled the urinary AGE (uAGE) clearance $(p<0.01)$. B) LZ stimulated the uptake and degradation of ${ }^{125}$ I-labeled AGE-BSA and ${ }^{25}$ I-human serum AGE by Mf, while suppressing AGE-induced TNF $\alpha$ and IGF-I production. In MC, LZ suppressed the AGE-promoted PDGF-B, $\alpha$ l type IV collagen, and tenascin mRNA levels, and restored the AGE-suppressed expression and activity of MMP-9, but not MMP-2.

Conclusion: LZ may act to: a) accelerate renal in-vivo AGE clearance, b) suppress macrophage and mesangial cellspecific gene activation in vitro, and c) improve albuminuria due to diabetes. These data suggest that LZ by sequestering AGEs may protect against diabetic renal damage.

\section{Introduction}

Advanced glycation endproducts (AGE) are a heterogeneous group of compounds derived from the non-enzymatic interaction between reducing sugars and proteins $(1,2)$. The formation of AGE is a ubiquitous biochemical process accompanied by the generation of reactive oxygen species (ROS) $(3,4)$. Over the past twenty years, the pathogenicity of AGE has been extensively studied, especially in connection with diabetes and age-related diseases that are associated with elevated levels of AGE production. Certain reactive AGE precursors, such as methylglyoxal (MG), 1,3-deoxyglucosone, and protein-linked Amadori product-dione, have been identified as potentially pathogenic intermediates in tissue injury $(1,2)$. AGE

Send correspondence and reprint requests to: Helen Vlassara, Mount Sinai School of Medicine, One Gustave L. Levy Place, Box 1640, New York, NY 10029-6574, USA. Phone: 212-659155 1; fax: 212-849-2652; e-mail: helen.vlassara@mssm.edu. precursors can react with serum or tissue components and, with the production of oxidative species, directly alter the physical and structural properties of tissue components (5-8). In addition, AGE elicit a wide range of cell-mediated responses, thereby inducing phenotypic changes that lead to reactive oxygen species (ROS) generation, inflammatory cell activation, and growth factor/cytokine production $(1,3,9$, $10)$, often via AGE-specific receptors $(3,9)$. Under conditions of excessive circulating or tissue AGE levels, as in diabetes, aging, and renal insufficiency, AGEmediated pathologies are more pronounced. Inhibition of AGE accumulation, through anti-AGE agents (11-13) or via dietary AGE restriction $(14,15)$, prevents renal and vascular abnormalities in diabetic and aging animals, confirming the causal role for AGE in tissue damage and in diabetic pathologies.

Lysozyme (LZ) is a well-characterized, naturally occurring protein that exerts anti-microbial effects through the catalytic degradation of the peptidoglycan 
components of the bacterial cell wall (16). We have recently reported the previously unrecognized ability of lysozyme to bind AGE with high affinity ( $\mathrm{Kd}=$ $50 \mathrm{nM})(17,18)$. The AGE-binding site was mapped to a 17-amino acid hydrophilic domain, bounded by cysteines, located within one of the two LZ catalytic regions. This AGE-binding cysteine-bounded domain, termed the ABCD loop (17), was shown to bind AGE species including tissue-reactive derivatives found in circulation (18), suggesting that LZ could be used for the capture, sequestration and disposal of toxic AGE formed in vivo.

In this study, we investigated the in-vivo effects of hen egg LZ on serum AGE (sAGE) clearance and renal excretion under normal and diabetic conditions. In addition, we have begun to explore the cellular mechanism of LZ action, with particular emphasis on macrophage and mesangial cell AGE-activation.

\section{Materials and Methods}

\section{Reagents}

Hen egg white lysozyme (LZ), D-glucose, cyanogen bromide-activated Sepharose 4B, and p-nitrophenyl phosphate tablets, glyoxylic acid, methylglyoxal and $\mathrm{NaBH}_{3} \mathrm{CN}$ were purchased from Sigma Chemical Co. (St. Louis, MO, USA). Rabbit anti-hen egg lysozyme antisera were from Biodesign (ME, USA). Sodium ${ }^{125}$ I-iodide was purchased from DuPont-Merck Pharmaceutical Co. (Wilmington, DE, USA). Lowendotoxin bovine serum albumin (BSA) (Sigma Chemical Co.) was passed sequentially over an AffiGel Blue column (Bio-Rad Laboratories, Hercules, CA, USA), a heparin-Sepharose CL6B column (Pharmacia, LDB, Uppsala, Sweden), and an endotoxinbinding affinity column (Pierce, Rockford, IL, USA) to remove various contaminants. BSA prepared in this manner then was incubated with or without $0.5 \mathrm{M}$ D-glucose in $0.2 \mathrm{M}$ phosphate buffer $\left(\mathrm{pH} \mathrm{7.4)}\right.$ ) at $37^{\circ} \mathrm{C}$, for 4 weeks under sterile conditions. Low molecular weight reactants and free glucose were removed by dialysis against phosphate buffered saline (PBS), as previously described (19). AGE levels, measured by an anti-AGE monoclonal antibody that recognizes CML-like epitopes (20) were: AGE-BSA, $250 \mathrm{U} / \mathrm{mg}$ protein; unmodified BSA, $0.9 \mathrm{U} / \mathrm{mg}$ protein. Methylglyoxal- (MG) and $\mathrm{N}^{\varepsilon}$-carboxymethyllysine (CML)modified BSA were prepared according to previously published procedures $(21,22)$. Briefly, MG-BSA was prepared by incubating BSA $(20 \mathrm{mg} / \mathrm{mL})$ with $150 \mathrm{mM}$ MG in the presence of $\mathrm{NaBH}_{3} \mathrm{CN}(0.45 \mathrm{M})$, in PBS (0.1 M, pH 10.0), followed by overnight dialysis against PBS at $4^{\circ} \mathrm{C}$. CML-BSA was prepared by incubating BSA in $0.2 \mathrm{M}$ PBS, $\mathrm{pH} 7.8$, containing glyoxylic acid $(0.15 \mathrm{M})$ and $\mathrm{NaBH}_{3} \mathrm{CN}(0.45 \mathrm{M})$ for $24 \mathrm{~h}$ at $37^{\circ} \mathrm{C}(22)$. BSA derivatives were dialyzed and kept frozen at $-80^{\circ} \mathrm{C}$. GC-MS analyses indicated that MG-BSA contained 22.4 modified arginine and 10 modified lysine residues/molecule, and CML-BSA contained 21 modified lysines/ molecule. Aliquots of each protein preparation, as well as of human diabetic sera (see below), were iodinated using Iodo-Beads (Pierce). After TCA (20\%) precipitation, $\sim 95 \%$ of ${ }^{125} \mathrm{I}$ was protein-bound (specific activity: $\sim 0.8-1.0 \times 10^{3}$ $\mathrm{cpm} / \mathrm{ng}$ of protein). TNF $\alpha$ and IGF-I were determined by a mouse TNF $\alpha$ immunoassay kit (Biosource International, Camarillo, CA, USA) and a rat IGF-I immunoassay kit (Diagnostic System Laboratory Inc, Webster, TX, USA), respectively.

\section{Isolation of Human Serum AGE-proteins}

Human serum samples were obtained from 10 diabetic patients with advanced renal insufficiency (age: $60 \pm 8$, years of diabetes: $16 \pm 4$, HbAlc: $7 \%$ ), stored at $-80^{\circ} \mathrm{C}$, and used as a source of in-vivo-formed AGEproteins. Human serum AGE-proteins were enriched by the use of an AGE-affinity column prepared as previously described (18). Briefly, lysozyme was conjugated to cyanogen-bromide-activated Sepharose 4B beads. Samples were diluted 1:5 with PBS just before loading on the column (bed volume, $2 \mathrm{ml}$ ). After collecting pass-through fractions, columns were washed and bound fractions $(0.5 \mathrm{ml} /$ fraction $)$ were eluted with $0.1 \mathrm{~N} \mathrm{NaOH}$, and neutralized immediately with $\mathrm{HCl}$; protein concentration was determined by BCAprotein analysis (Pierce). AGE levels were determined by ELISA $(19,20)$.

\section{Animals}

Male Sprague-Dawley rats (350-375 g, Jackson Laboratories, Bar Harbor, ME, USA) were divided into 3 groups $(n=5 /$ group $)$ and injected intraperitoneally (i.p. $200 \mu$ l PBS) daily for 12 days with either AGEmodified BSA (40 mg/day) (group A), AGE-modified BSA $(40 \mathrm{mg} /$ day) plus hen egg LZ (200 mg/day) (group B), or LZ alone (200 mg/day) (group C). Serum and $24 \mathrm{~h}$-urine samples were collected at baseline and at the end of study, (each time for 3 consecutive days) for creatinine and AGE clearance $(23,24)$. Rat or mouse serum was separated into low (LMW) $(<10 \mathrm{kD})$ and high (HMW) AGE-peptide fractions as described (5). The LMW-peptide AGE values were used for calculation of AGE clearance (5).

Pre-diabetic, male, non-obese diabetic (NOD) mice (25-27 g, n = 5/group, Jackson Laboratories) were injected i.p., daily, for 14 days, with LZ in PBS (2 mg LZ/0.5 ml PBS/day), or PBS (0.5 ml PBS/day). In addition, ten C57BL/KsJ, $\mathrm{db} / \mathrm{db}(+/+)$ mice (female, 5 month-old, Jackson Laboratories) with fasting glycemias at $390-450 \mathrm{mg} / \mathrm{dL}$ were randomly divided into two groups $(\mathrm{n}=5$ /group). Each group received i.p. for 14 days either LZ in PBS $(6 \mathrm{mg}$ LZ/0.5 ml PBS/day) or PBS $(0.5 \mathrm{ml} /$ day $)$. Weightmatched control SJL mice and $\mathrm{db} / \mathrm{m}(+/-)$ (Jackson Laboratories) $(n=10 /$ group $)$ were injected with PBS $(0.5 \mathrm{ml})$ alone. All animals were given free access to rat chow and water. At the end of the study, animals were sacrificed by decapitation, and blood, urine and kidneys were collected. Kidney cortices were snap-frozen in liquid nitrogen immediately 
for total RNA, membrane protein, and total protein extraction. Kidney tissue was homogenized and digested as described $(23,24)$, and together with aliquots of serum and urine were used for AGE determination by an AGE-ELISA $(19,20)$. Twentyfour-hour urine creatinine levels were determined by a standard kit (Stanbio Laboratories, San Antonio, TX, USA) and albumin levels by ELISA $(23,24)$.

\section{Cells and Cell Assays}

Macrophages Murine macrophage-like TIB-183 cells (ATCC, Rockville, MD, USA) were maintained in DMEM medium, supplemented with penicillin (100 units $/ \mathrm{ml})$, streptomycin $(100 \mu \mathrm{g} / \mathrm{ml})$, and $10 \%$ fetal bovine serum (Gibco, Gaithersburg, MD, USA) at $37^{\circ} \mathrm{C}$ and $5 \% \mathrm{CO}_{2}$. Cells $\left(1 \times 10^{6}\right.$ cells/well $)$ were grown to confluency in 12-well culture plates and were then incubated in binding medium consisting of complete DMEM medium and $1 \%$ BSA for $30 \mathrm{~min}$ at $4^{\circ} \mathrm{C}$ prior to further studies. For cell binding studies, ${ }^{125}$ I-labeled AGE-BSA, BSA or LZ $(30-50 \mu \mathrm{g} / \mathrm{ml})$ were each added, in the presence or absence of 100 -fold excess of unlabeled AGE-BSA, BSA, LZ, respectively, for $2 \mathrm{hrs}$ at $4^{\circ} \mathrm{C}(24,25)$. For cellular uptake and degradation studies, similar experiments were performed using ${ }^{125} \mathrm{I}$-AGE-BSA $(200 \mu \mathrm{g} / \mathrm{ml})$ in the presence or absence of LZ $(100 \mu \mathrm{g} / \mathrm{ml})$ at $37^{\circ} \mathrm{C}$ for up to $24 \mathrm{hrs}$. Also, radiolabeled AGE-enriched human sera $(200 \mu \mathrm{g} / \mathrm{ml})$ were added to macrophages with or without LZ $(100 \mu \mathrm{g} / \mathrm{ml})$ for $4 \mathrm{hrs}$ at $37^{\circ} \mathrm{C}$. Cells were washed extensively with cold PBS and lysed using 0.1 M NaOH. The radioactivity and protein content (BCA-protein analysis, Pierce) in each sample were measured. The culture media were collected, TCA-precipitated, and the radioactivity and protein content determined. All experiments were carried out in triplicate.

Mesangial Cells Glomerular mesangial cells (MC) from normal C57BL/6 mice (4 months old) were isolated and characterized, as described $(24,26,27)$. Cell preparations were cultured in complete medium $(2 / 3$ DMEM and 1/3 F12, supplemented with $1 \mathrm{mM}$ glutamine, 100 units $/ \mathrm{ml}$ penicillin, $100 \mu \mathrm{g} / \mathrm{ml}$ streptomycin, and $10 \%$ fetal bovine serum) (Gibco) at $37^{\circ} \mathrm{C}$ in $5 \% \mathrm{CO}_{2}$. Cells were passaged weekly and used for no more than 8-10 passages.

\section{Ligand Blot, mRNA and Protein Analyses}

For ligand blot analysis, $10 \mu \mathrm{g}$ of LZ were transferred onto nitrocellulose (NC) membranes $(0.2 \mathrm{~mm}$ pore size) using a mini-gel transfer apparatus (Bio-Rad Laboratories). The NC membranes were blocked with $2 \%$ BSA in PBS for $1 \mathrm{hr}$, washed twice with PBS containing $0.05 \%$ Tween-20 and probed with ${ }^{125} \mathrm{I}-\mathrm{MG}$-modified BSA $\left(2 \times 10^{6} \mathrm{cpm}\right)$ for $1 \mathrm{hr}$ in the presence or absence of 50-fold excess cold AGEBSA, BSA, CML-BSA or MG-BSA. The blots were washed extensively with PBS/Tween-20, air dried and exposed to XAR film (Kodak) at $-80^{\circ} \mathrm{C}$. The radioactivity associated with each blot was quantified by a phosphorimager (Packard) and expressed as $\%$ cpm of control (uncompeted MG-BSA). This procedure was repeated at least three times.

Total RNA was extracted from cultured macrophages or mesangial cells using the phenol extraction method (RNAzol solution, TEL TEST Inc., Friendswood, TX, USA). For each extraction, RNA content was measured and equal quantities of RNA were added to reverse transcriptase reactions using a first-strand cDNA synthesis kit (Boehringer Mannheim Biochemicals Inc., Indianapolis, IN) $(28,29)$. The primers used in PCR assays were as follows.

TNF $\alpha$, sense: $5^{\prime}$-ACT GAA CTT CGG GGT GAT CGG TCC-3'; antisense: 5'-CAG CCT TGT CCC TTG AAG AGA ACC-3', yielding a 293 bp product.

IGF-I, sense: $5^{\prime}$-GGC TGC TTT TGT AGG CTT CAG TGG-3'; antisense: 5'-GGA CCA GAG ACC CTT TGC GGG G-3', yielding a 211 bp product.

Tenascin, sense: 5'-TAC GAC AGA TTC AGT GTT GG-3'; antisense: 5' -TTG TAG ACT GTT GTC TTT GG-3', yielding a 548 bp product.

$\alpha_{1}$ type IV collagen, sense: 5'-TAG GTG TCA GCA ATT AGG-3'; antisense: 5'-TCA CTT CAA GCA TAG TGG TCC G-3', yielding a 484 bp product. TTA AGG TGG TGC AGG TAT CTG G-3', yielding a $701 \mathrm{bp}$ product.

MMP-2 sense: 5'-CTT TGC AGG AGA CAA GTT CTG G; antisense: 5' TAA AGG TGG TGC AGG TAT CTG G-3', yielding a $701 \mathrm{bp}$ product.

MMP-9 sense: $5^{\prime}$-ATG TGG TTA TGT TCA CAT GC3'; antisense: 5'-ATG CTT CCT GGA TCA GTT CC-3', yielding a 472 bp product.

Platelet-derived growth factor (PDGF)-B sense: $5^{\prime}$ TGT GAG ACA ATA GTG ACC-3'; antisense: 5'TTG GAG TCA AGA GAA GCC-3', yielding a 432 bp product.

TGF- $\beta 1$ sense: 5 -ATA CAG GGC TTT CGA TCC AGC-3'; antisense: 5'-GTC CAG GCT CCA AAT ATA GG-3', yielding a 360 bp product.

$\beta$-actin sense: $5^{\prime}$-TCA TGA GGT AGT CCG TCA GG-3'; antisense: 5'-TCT AGG CAC CAA GGT GTG-3', yielding a 460 bp product.

GAPDH sense: 5'-CAA AGT TGT CAT GGA TGA CC-3'; antisense: 5'-TCC TCC CTG TTC TAG AGA CAG-3', yielding a 561 bp product.

To establish the linear range of PCR amplification for the above molecules, we plotted increasing numbers of PCR cycles against the integrated optical density obtained from computer-aided densitometry. The optimized PCR cycles were 30 for TNF; 30 for IGF-1; 24 for Tenascin; 23 for $\alpha_{1}$ type IV collagen; 32 for MMP-2; 34 for MMP-9; 30 for PDGF-B; 30 for TGF- $\beta 1 ; 24$ for $\beta$-actin and 20 for GAPDH. There were no changes in the "housekeeping" genes, $\beta$-actin and GAPDH expression levels in cells treated with or without AGE (data not shown). Since the levels of $\beta$-actin and GAPDH mRNA were 
comparable in each of our cDNA samples, PCR data was normalized to $\beta$-actin as a control of interassay variance $(28,29)$. At least 5 RT-PCRs were conducted for each primer pair using cells from separate preparations.

\section{Tumor Necrosis Factor (TNF)- $\alpha$ and Insulin-like Growth} Factor-I (IGF-I) Protein Assessment

Cells from the mouse macrophage cell line TIB-183 (ATCC, Rockville, MD, USA) were plated at $10^{6}$ cells/ well into 6-well plates with RPMI 1640 and 10\% FCS medium at $37^{\circ} \mathrm{C}$ and $5 \% \mathrm{CO}_{2}$. After $24 \mathrm{~h}$, cells were washed three times with PBS and incubated with AGE-modified BSA, BSA (100 $\mu \mathrm{g} / \mathrm{ml})$, or MGBSA $(25 \mu \mathrm{g} / \mathrm{ml})$, in the presence or absence of $100 \mu \mathrm{g} / \mathrm{ml} \mathrm{LZ} \mathrm{for} 24$ hrs. Rabbit anti-hen egg LZ antibody $(50 \mu \mathrm{g} / \mathrm{ml})$ was added in a separate series together with LZ (100 $\mu \mathrm{g} / \mathrm{ml})$ to test the specificity of the LZ effects. Pre-immune rabbit IgG was used as control. Total RNA was extracted from cells $24 \mathrm{hrs}$ after treatment, and reverse-transcribed with random primers, as described above $(24,28,29)$. Secreted TNF $\alpha$ and IGF-I were determined in the medium at $48 \mathrm{hrs}$, using a mouse $\mathrm{TNF} \alpha$ immunoassay kit (Biosource International, Camarillo, CA, USA) and a rat IGF-I immunoassay kit (Diagnostic System Laboratory Inc, Webster, TX, USA), respectively.

PDGF-B, $\alpha_{1}$ Type IV Collagen, Tenascin, and MMP-2 and MMP-9 in Mesangial Cell

Mesangial cells (MC) were plated in 6-well plates at a density of $1 \times 10^{5}$ cells/well in DMEM/F12 $+20 \%$ fetal calf serum (FCS) as previously described $(24,26)$. Twenty-four $h$ later, the cells were washed twice with PBS and the culture medium was replaced with DMEM/F12 + 0/5\% FCS. AGE-BSA $(800 \mu \mathrm{g} / \mathrm{ml})$ or native BSA $(800 \mu \mathrm{g} / \mathrm{ml})$ was added with or without hen egg LZ $(400 \mu \mathrm{g} / \mathrm{ml})$. Cells were collected after 72 hours of incubation. Cellular RNA extraction and quantitative RT-PCR analysis was performed as described $(26,29)$, using the primers described above. $\beta$-actin and GAPDH were used as housekeeping genes. Because both genes provided identical results, only $\beta$-actin data are shown.

\section{MMP Activity}

Mesangial cell MMP-2 and MMP-9 expression and activity were assessed $(30,31)$. MC $\left(1 \times 10^{6} /\right.$ well $)$ were incubated with DMEM/F12 $+0.1 \%$ BSA in the presence of AGE-BSA or BSA $(300 \mu \mathrm{g} / \mathrm{ml})$ with or without lysozyme $(150 \mu \mathrm{g} / \mathrm{ml})$. After $24 \mathrm{~h}$, the cell culture medium was collected and loaded onto a $10 \%$ gelatin gel (BioRad). The gel was then incubated with $2.5 \%$ Triton-X at room temperature for 1 $\mathrm{h}$, and then placed in collagenase buffer $(50 \mathrm{mM}$ Tris, $\mathrm{pH} 7.5,150 \mathrm{mM} \mathrm{NaCl}, 10 \mathrm{mM} \mathrm{CaCl}_{2}, 0.2 \%$ Brij-35) at $37^{\circ} \mathrm{C}$ for $24 \mathrm{~h}$. Gelatinase activity was visualized by staining the gel with $0.5 \%$ Coomassie Blue, and subsequent destaining with $30 \%$ methanol and $10 \%$ acetic acid.
Statistics

Analysis of variance and Student's $t$ test (unpaired, two-tailed) were used to analyze differences between groups. $\mathrm{P}$ values $<0.05$ were considered statistically significant.

\section{Results}

LZ Reduces Endogenously-formed Serum AGE and Increases Renal AGE Excretion

To test the ability of LZ to lower in-vivo formed sAGE, we studied non-obese-diabetic (NOD) mice. While less susceptible to diabetes, male NOD are more susceptible to nephropathy and importantly they exhibit elevated serum AGE levels (24), which provided the advantage of examining LZ effects on elevated native AGE in vivo, but in the absence of hyperglycemia, studied below in the $d b / d b$ mouse strain. As expected (24), NOD mice exhibited higher sAGE levels than control mice $(31.5 \pm 6.7 \mathrm{vs} 14.2 \pm 5 \mathrm{U} / \mathrm{ml}$, $\mathrm{p}<0.05)$. The administration of $\mathrm{LZ}$ for 14 days decreased NOD serum AGE levels to $22.3 \pm 5 \mathrm{U} / \mathrm{ml}$, $\mathrm{p}<0.05$, an effect accompanied by a significant and proportional increase in urinary AGE excretion by 1.8 -fold at 2 weeks (from $200 \pm 71.4 \mathrm{U} / \mathrm{ml}$ to $367.9 \pm 41.2 \mathrm{U} / \mathrm{ml}, \mathrm{p}<0.05)$. These effects occurred without significant changes in creatinine clearance, nor in fasting blood glucose or body weight (Table 1). No effect in SAGE nor in uAGE was seen after administration of PBS as control (not shown).

The effect of 2-week LZ administration was also tested in a spontaneously diabetic $d b / d b(+/+)$ mouse model, exhibiting type II diabetes, obesity and insulin resistance. LZ treatment reduced the elevated baseline sAGE levels in these mice (from $37.9 \pm$ 3.8 to $26.2 \pm 5.3 \mathrm{U} / \mathrm{ml}, \mathrm{p}<0.05$, control: $21.5 \pm 7.7$ $\mathrm{U} / \mathrm{ml}$ ), and nearly doubled the urinary excretion of AGE (from $92.7 \pm 52.6$ to $170.9 \pm 49.5 \mathrm{U} / \mathrm{ml}$, $\mathrm{p}<0.05)$, made more evident when expressed as AGE clearance $(p<0.01)$ (Table 1$)$. These effects were not associated with changes in creatinine clearance, fasting blood glucose $(320 \pm 130 \mathrm{mg} / \mathrm{dL}$ before vs. $290 \pm 60 \mathrm{mg} / \mathrm{dL}$ after), or body weight. No effects on sAGE or UAGE clearance were observed in NOD mice injected with PBS alone (data not shown).

Baseline urinary albumin (UA) levels in both NOD and $d b / d b$ mice were moderately increased over those of normal controls. Over the two-week period during which NOD mice were injected with LZ, UA declined by $35 \%(p<0.005)$. Similarly, LZ treatment of $\mathrm{db} / \mathrm{db}$ mice reduced UA excretion by $65 \%(\mathrm{p}<0.01)$ (Table 1$)$.

The time-dependent effects of LZ administration were tested on normal rats infused with exogenous AGE-BSA. While in rats administered AGE alone (Group A), serum AGE (sAGE) levels rose significantly and reached a 2.2-fold increase above baseline within 12 days $(p<0.01)$, in rats administered both AGE and LZ (Group B), sAGE levels remained near baseline despite continuing AGE infusion for 12 days 
Table 1. Effect of a 2-week course of LZ administration on physiological serum and urine characteristics of NOD and $\mathrm{db} / \mathrm{db}$ mice

\begin{tabular}{|c|c|c|c|c|c|c|}
\hline \multirow[b]{2}{*}{ Treatment (LZ) } & \multirow{2}{*}{$\begin{array}{c}\text { SJL } \\
(n=10)\end{array}$} & \multicolumn{2}{|c|}{$\begin{array}{l}\text { NOD } \\
(n=5)\end{array}$} & \multirow{2}{*}{$\begin{array}{l}\mathrm{db} / \mathrm{m} \\
(\mathrm{n}=10)\end{array}$} & \multicolumn{2}{|c|}{$\begin{array}{c}d b / d b \\
(n=5)\end{array}$} \\
\hline & & Baseline & 2-Weeks & & Baseline & 2-Weeks \\
\hline Weight $(\mathrm{g})$ & $25 \pm 3$ & $25.3 \pm 2.4$ & $26.8 \pm 1.6$ & $26.7 \pm 2.8$ & $48.9 \pm 1.5$ & $50.1 \pm 1.6$ \\
\hline Blood glucose $(\mathrm{mg} / \mathrm{dL})$ & $117 \pm 44$ & $128 \pm 20$ & $132 \pm 32$ & $121 \pm 27$ & $320 \pm 130$ & $290 \pm 60$ \\
\hline Serum AGE (U/ml) & $14.2 \pm 4.8$ & $31.5 \pm 6.7$ & $22.3 \pm 5.1^{*}$ & $21.5 \pm 7.7$ & $37.9 \pm 3.8$ & $26.2 \pm 5.3^{*}$ \\
\hline Serum $\mathrm{Cr}(\mathrm{mg} / \mathrm{dL})$ & $0.38 \pm 0.04$ & $0.42 \pm 0.02$ & $0.47 \pm 0.05$ & $0.33 \pm 0.06$ & $0.69 \pm .01 \#$ & $0.72 \pm 0.11 \# \#$ \\
\hline Urine AGE (U/ml) & $197 \pm 41$ & $200.3 \pm 71.4$ & $367.9 \pm 41.2^{*}$ & $103.8 \pm 37.5$ & $92.7 \pm 52.6$ & $170.9 \pm 49.5^{*}$ \\
\hline Urine Cr (ug/ml) & $357.3 \pm 77.9$ & $308.4 \pm 68.7$ & $324.9 \pm 50.3$ & $276.5 \pm 93.4$ & $207.6 \pm 31.7$ & $212.3 \pm 49.4$ \\
\hline $\operatorname{Ccr}(\mathrm{ml} / \mathrm{min})$ & $0.03 \pm 0.01$ & $0.04 \pm 0.008$ & $0.05 \pm 0.007$ & $0.05 \pm 0.02$ & $0.05 \pm 0.007$ & $0.05 \pm 0.01$ \\
\hline $\mathrm{C}_{\mathrm{AGE}}(\mathrm{ml} / \mathrm{min})$ & $0.004 \pm 0.0012$ & $0.003 \pm 0.0011$ & $0.008 \pm 0.0009^{* *}$ & $0.003 \pm 0.001$ & $0.004 \pm 0.002$ & $0.013 \pm 0.004^{* *}$ \\
\hline Urinary $\mathrm{Alb} / \mathrm{Cr}$ & $0.29 \pm 0.15$ & $0.92 \pm 0.32 \# \#$ & $0.53 \pm 0.24^{*}$ & $0.38 \pm 0.2$ & $1.13 \pm 0.45$ & $0.73 \pm 0.26^{*}$ \\
\hline
\end{tabular}

${ }^{*} \mathrm{p}<0.05,{ }^{* *} \mathrm{p}<0.01,2$ weeks LZ vs baseline. \#p $<0.05, \#$ \# $<0.01$, vs respective control group.

(Fig. 1A). In addition, in the LZ + AGE group (group B), LZ administration was associated with a timedependent increase in urinary AGE (uAGE) clearance (max. 2.1-fold) above the AGE alone group (Group $A)$, and in proportion to the reduction in sAGE (p < $0.01)$, although renal creatinine clearance remained stable $\left(98 \pm 12 \times 10^{-5} \mathrm{ml} \cdot \mathrm{min}^{-1}\right)$ throughout the experiment (Fig. 1B). Of note, control animals that were injected with LZ also exhibited a significant increase in endogenous UAGE excretion (50\% of untreated controls, $\mathrm{p}<0.01)$, which was associated with a similar decrease in SAGE levels, indicating a salutary LZ effect on normally excretable AGE.

Lysozyme Increases the Macrophage Binding, Endocytosis and Degradation of $A G E$

In vivo studies (Table 1) and (Fig. 1) demonstrate that, full-length LZ-polypeptide administered to either spontaneously diabetic mouse models or nondiabetic AGE-infused rats, reduces super-normal levels of circulating AGE (sAGE) within a period of 2 weeks. While this effect is attributable, at least in part, to increased renal clearance of AGE, other indirect mechanisms might be involved, including cellular sequestration, and processing of AGE bound by $\mathrm{LZ}$ before their release from tissues into the circulation and ultimately in the urine. To examine the cell-related uptake of AGE in the presence of $\mathrm{LZ}$, we examined two relevant cell types, macrophages and primary mouse mesangial cells, both known to interact with AGE $(9,24,26,28)$.

Macrophage surface-binding of ${ }^{125} \mathrm{I}-\mathrm{AGE}-\mathrm{BSA}$ exhibited the expected AGE-specific pattern, based on its effective inhibition by added AGE ligand. In the presence of LZ, AGE-specific binding increased significantly (Fig. 2A). In contrast, ${ }^{125}$ I-LZ binding by these cells when added alone was not significant, nor did it change in the presence of additional LZ, a result similar to that obtained using native ${ }^{125} \mathrm{I}-\mathrm{BSA}$ as control, indicating that LZ interacted only minimally
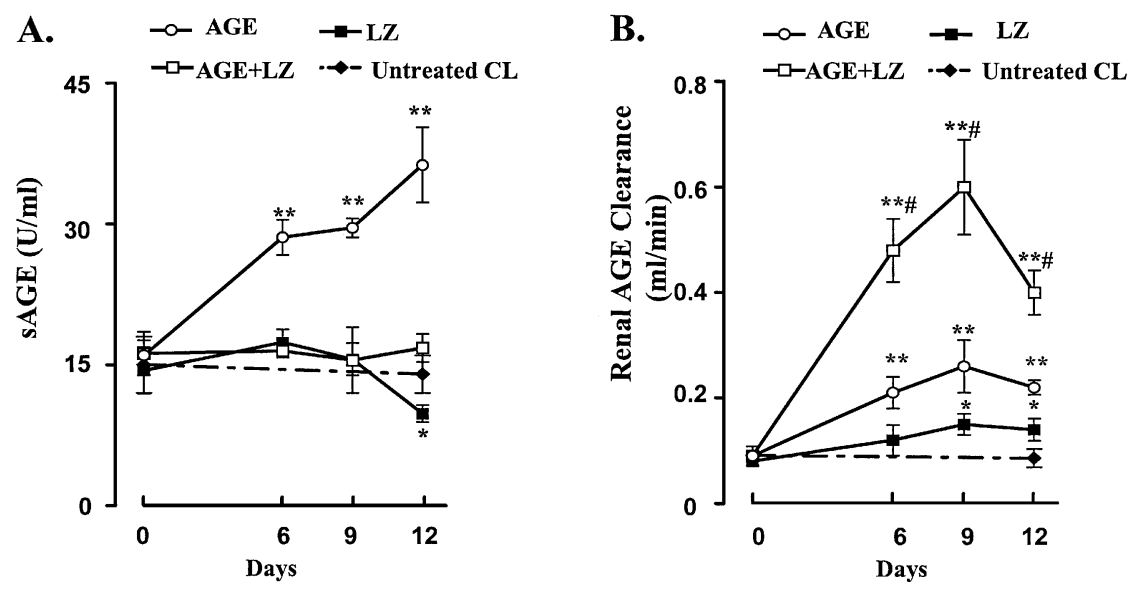

Fig. 1. Lysozyme reduces serum AGE (A) and enhances renal AGE-clearance (B) in AGE-treated, non-diabetic rats. AGE-BSA (40 mg), AGE-BSA (40 mg) + hen egg LZ (200 mg), LZ (200 mg) or PBS were injected daily i.p. into normal rats ( $\mathrm{n}=5$ /group) for 12 days. Serum AGE (sAGE) levels are expressed as $\mathrm{U} / \mathrm{ml}$ and urinary AGE clearance as $\mathrm{ml} / \mathrm{min}$. Each point represents the mean \pm standard deviation $(\mathrm{M} \pm \mathrm{SD})$ of triplicate values obtained from each animal group. ${ }^{* *} \mathrm{p}<0.01$ vs control, $* \mathrm{p}<0.05$ vs. control, \#p $<0.01$ vs AGE + LZ group. 
A.

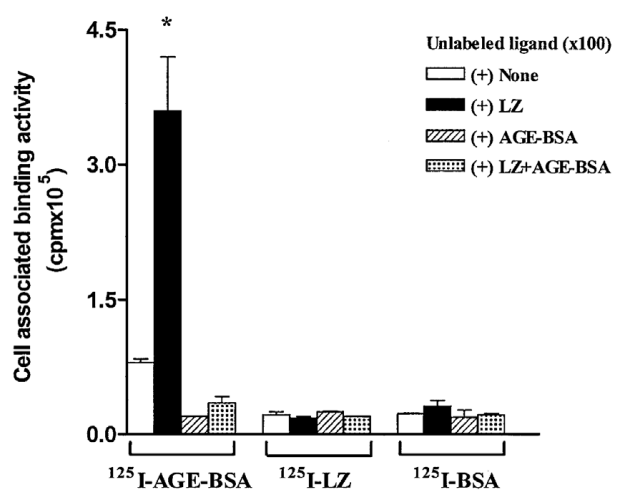

C.

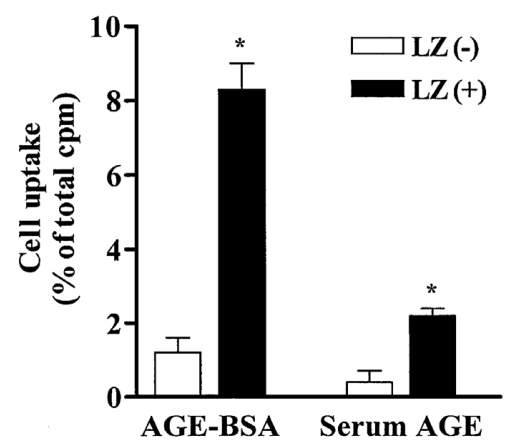

B.

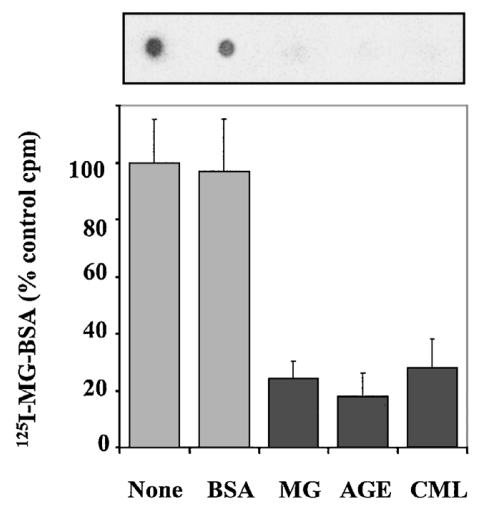

D.

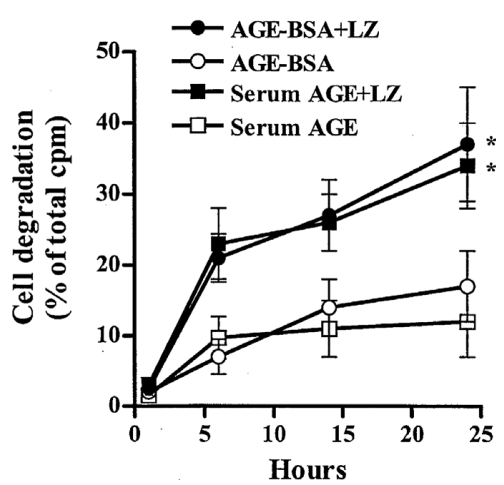

Fig. 2. Lysozyme enhances macrophage binding, internalization and degradation of AGE formed in vitro or in human sera. (A) Confluent cultures of murine macrophage-like T1B-183 cells $\left(0.5 \times 10^{6} /\right.$ well) were incubated with either ${ }^{125} \mathrm{I}_{-} \mathrm{AGE}-\mathrm{BSA}$, ${ }^{125} \mathrm{I}$-LZ or ${ }^{125} \mathrm{I}$-BSA (10-25 $\left.\mathrm{g} / \mathrm{well}\right)$, in the presence or absence of 100-fold excess of the indicated unlabeled ligand, for $2 \mathrm{hrs}$ at $4{ }^{\circ} \mathrm{C}$. (B) LZ was immobilized on a NC membrane $(10 \mu \mathrm{g} / \mathrm{dot})$ and probed with ${ }^{125} \mathrm{I}-\mathrm{MG}$-BSA $\left(4 \times 10^{6} \mathrm{cpm}\right.$, or $\left.5 \mu \mathrm{g} / \mathrm{ml}\right)$ in the presence or absence of 50-fold excess of unlabeled AGE-BSA, MG-BSA, CML-BSA or BSA for $1 \mathrm{hr}$. Radiolabeled ligand binding was visualized by exposure to XAR film (Kodak) at $-80^{\circ} \mathrm{C}$ (upper), and quantitated by phosphorimage analysis of three identical ligand dot blots, expressed as $M \pm S D$ (lower). (C) T1B-183 cells, plated as in (A) were incubated with either ${ }^{125}$ I-labeled AGE-BSA (100 $\left.\mu \mathrm{g} / \mathrm{well}\right)$ or ${ }^{125} \mathrm{I}$-human AGE-enriched serum $(150 \mu \mathrm{g} / \mathrm{well})$ with or without LZ $(80 \mu \mathrm{g} / \mathrm{ml})$ for $4 \mathrm{hrs}$ at $37^{\circ} \mathrm{C}$. (D) Media from T1B-183 cell cultures treated as in (C) were collected and after TCA-precipitation, soluble cpm were determined. For (A) (C) and (D) panels, data are expressed as the $M \pm S D$ cpm of five independent experiments, each performed in triplicate. ${ }^{*} p<0.05$, ${ }^{* *} p<0.01$ vs. LZ.

with the cell surface and in a non-specific manner. In a separate study, LZ immobilized onto a NC membrane was incubated with ${ }^{125}$ I-MG-modified BSA $\left(1 \times 10^{6} \mathrm{cpm} / \mathrm{ml}\right)$ in the presence or absence of 50 fold excess unlabelled AGE-modified BSA, MG, CML or native BSA. As shown in Fig. $2 \mathrm{~B},{ }^{125} \mathrm{I}-\mathrm{MG}-$ BSA bound onto LZ in a manner that was competitively inhibited by excess MG, AGE-BSA, or CML, but not by unmodified BSA, confirming that AGE recognition and binding by LZ included specific glycoxidative species found in vivo, such as MG or CML.

Furthermore, endocytosis and degradation of ${ }^{125}$ I-AGE-BSA or ${ }^{125}$ I-human serun AGE by macrophages were also enhanced in the presence of LZ (at $37^{\circ} \mathrm{C}$ ) (Fig. 2, C-D).

\section{LZ Suppresses AGE-mediated Macrophage Activation}

Since AGE also induce gene activation in several cellular systems $(3,9)$, we examined the effect of LZ on select AGE-dependent responses. The AGE-induced elevation of TNF $\alpha$ mRNA levels was abrogated in the presence of LZ (Fig. 3, A-B). Also, the AGEstimulated expression of IGF-I mRNA was inhibited in the presence of LZ (Fig. 3, E-F). Of note, the effects of LZ were reversed by the addition of anti-LZ antibody. Furthermore, when added to cells, the MGenhanced TNF $\alpha$ mRNA expression was also abrogated in the presence of LZ (Fig. 3, C-D). Also, LZ blocked the enhancing effect of AGE on macrophage TNF $\alpha$ and IGF-I protein secretion (Fig. 4, A-B).

\section{LZ Suppresses AGE-mediated Mesangial Cell Activation}

As noted previously $(3,26)$, normal mouse mesangial cells after incubation with AGE exhibited enhanced expression of PDGF-B, $\alpha_{1}$ type IV collagen and tenascin mRNA; however, in the presence of LZ, this response was inhibited (Fig. 5, A-C). LZ alone had no effect in any of these studies (Table 2).

Extracellular matrix is under the regulatory control of an important family of proteolytic enzymes, the metalloproteinases (MMP), including MMP-2 and MMP-9, believed to be important to the kidney. AGE 

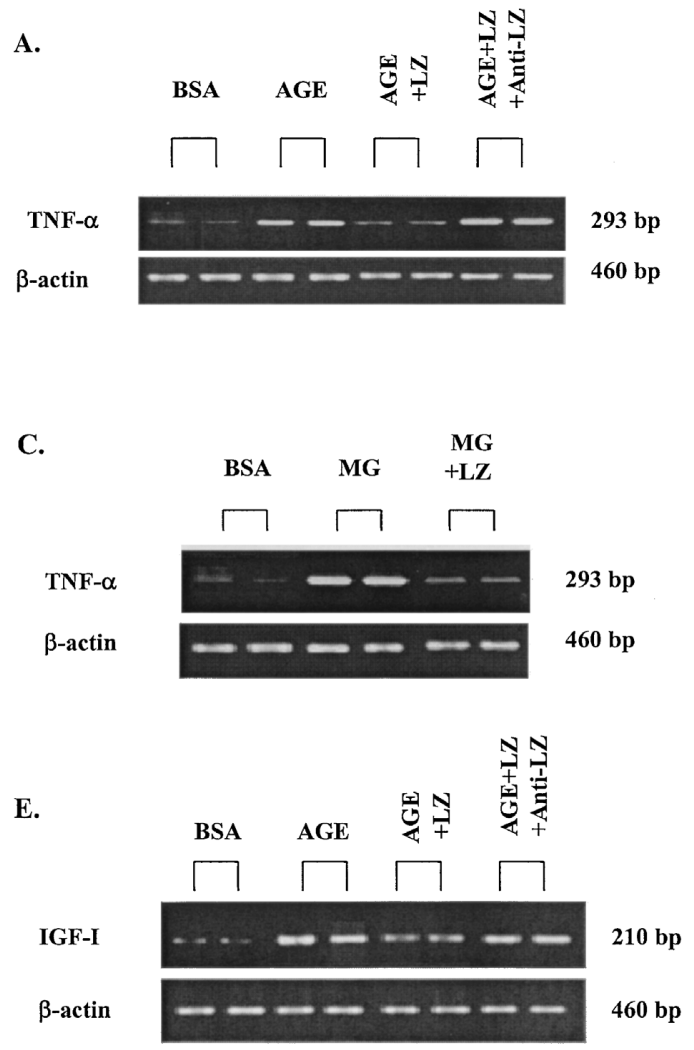

B.

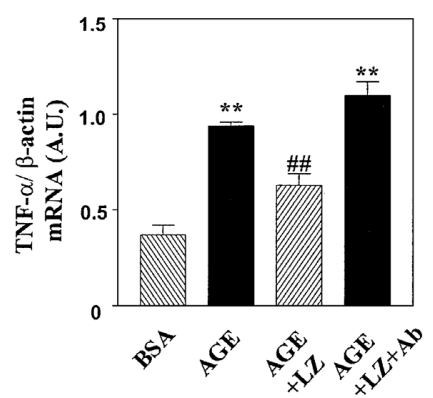

D.

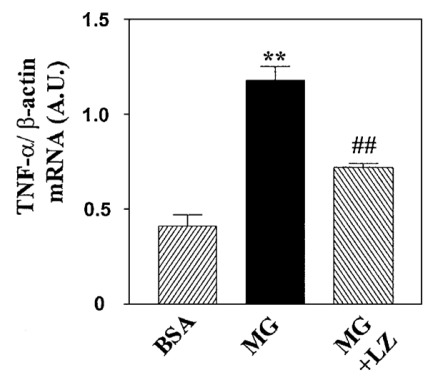

F.

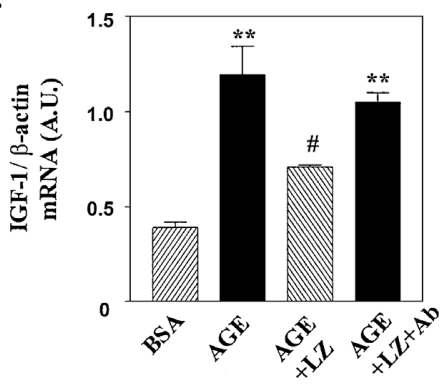

Fig. 3. Lysozyme suppresses AGEmediated macrophage gene induction. Confluent cultures of murine macrophagelike T1B-183 cells $\left(1 \times 10^{6} /\right.$ well $)$ were incubated with either AGE-BSA $(200 \mu \mathrm{g} / \mathrm{ml})$ or, BSA $(200 \mu \mathrm{g} / \mathrm{ml})$, in the presence or absence of LZ $(100 \mu \mathrm{g} / \mathrm{ml})$, which was added with or without anti-LZ antiserum $(50 \mu \mathrm{g} / \mathrm{ml})$ for up to $24 \mathrm{hrs}$ at $37^{\circ} \mathrm{C}$. Total RNA was extracted for TNF $\alpha$ $(\mathrm{A}, \mathrm{B})$, and IGF-I (E,F) mRNA assessment by RT-PCR. (C,D) MG-BSA $(25 \mu \mathrm{g} / \mathrm{ml})$ was added to T1B-183 cells with/without LZ $(100 \mu \mathrm{g} / \mathrm{ml})$ and RNA was extracted for TNF $\alpha$ mRNA testing by RT-PCR. $\beta$-actin is shown as an internal control gene. Data are representative of at least three identical experiments, each done in duplicate. exerted a markedly suppressive effect on MMP-9 gene expression, estimated to be $\sim 55 \%$ below control, based on RT-PCR and densitometric analysis (Fig. 5, A-B), but no effect of AGE was seen on MMP-2 mRNA (data not shown). AGE also suppressed MMP9 proteolytic activity against gelatin, but not of MMP2 based on zymography $(30,31)$ (Fig. 5, C-E). In the presence of LZ, however, AGE-mediated suppression of MMP-9 mRNA expression and proteolytic activity were ameliorated (Fig. 5, C-D).

\section{Discussion}

Pharmacological interventions aimed at bioactive AGE have been effective against the complications of diabetes and aging $(11,12,23)$. We have recently found that the well-known anti-bacterial protein lysozyme (LZ) contains an AGE-specific-binding, cysteinebounded domain, (ABCD motif), by which it can engage and sequester AGE-modified substances from diabetic serum $(17,18)$. In the present study, we explored the in-vivo effects of native (full-length) LZ polypeptide, employed as a soluble AGE receptor on the sequestration and removal of circulating AGE, using two murine diabetes models, with elevated endogenous, circulating AGE levels, and a non-diabetic rat model exogenously supplemented with AGE. Synthetically produced AGE-binding LZ-peptide (ABCD) has been found equally active in vitro
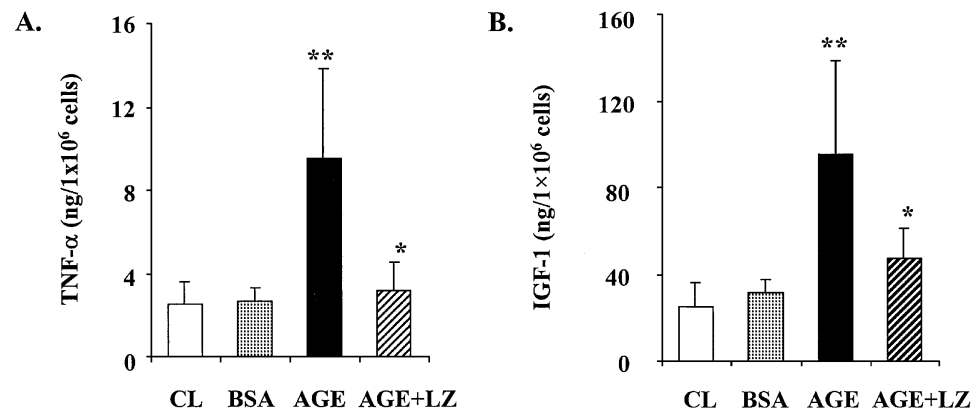

Fig. 4. Lysozyme suppresses AGE-mediated synthesis of TNF $\alpha$ and IGF-I by macrophages. Macrophage-like T1B-183 cells $\left(1 \times 10^{6} /\right.$ well $)$ were incubated with either AGE-BSA $(200 \mu \mathrm{g} / \mathrm{ml})$, BSA $(200 \mu \mathrm{g} / \mathrm{ml})$, or serum-free medium (CL) in the presence or absence of $\mathrm{LZ}(100 \mu \mathrm{g} / \mathrm{ml})$, for $48 \mathrm{hrs}$ at $37^{\circ} \mathrm{C}$. Conditioned media were tested for TNF $\alpha$ (A) and IGF-I (B) content by immunoassay. Data are expressed as the $\mathrm{M} \pm \mathrm{SD} \mathrm{ng} / \mathrm{well}\left(1 \times 10^{6}\right.$ cells $)$ of three identical experiments, each done in duplicate. ${ }^{*} \mathrm{p}<0.01$ vs. AGE, ${ }^{* *} \mathrm{p}<0.001$ vs. control. 
Table 2. LZ suppresses AGE-induced mesangial cell expression of growth promoting genes in culture ${ }^{\S}$

\begin{tabular}{lcccc}
\hline mRNA* & Control & LZ & AGE & AGE + LZ \\
\hline PDGF-B/ $\beta$-actin(A.U.) & $0.12 \pm 0.05$ & $0.164 \pm 0.04$ & $0.49 \pm 0.11^{* *}$ & $0.27 \pm 0.07 \#$ \\
TGF- $\beta$ 1/ $\beta$-actin (A.U.) & $0.21 \pm 0.04$ & $0.19 \pm 0.08$ & $0.24 \pm 0.09$ & $0.26 \pm 0.03$ \\
$\alpha 1$ (IV) $/ \beta$-actin (A.U.) & $0.27 \pm 0.07$ & $0.29 \pm 0.13$ & $0.74 \pm 0.12^{* *}$ & $0.39 \pm 0.06 \#$ \\
Tenascin/ $\beta$-actin (A.U.) & $0.05 \pm 0.01$ & $0.04 \pm 0.02$ & $0.19 \pm 0.06^{* *}$ & $0.07 \pm 0.02 \# \#$
\end{tabular}

${ }^{* *} \mathrm{p}<0.05$, vs Control. \#p $<0.05$, \#\#p $<0.01$, vs AGE.

${ }^{*}$ Data are expressed as the ratio of each faxtor cDNA/mutant to $\beta$-actin cDNA/mutant and are shown as the M \pm SD of three experiments, each performed in duplicate.

§Primary murine mesangial cell cultures $\left(1 \times 10^{5} /\right.$ well) were incubated with AGE-BSA (800 $\left.\mu \mathrm{g} / \mathrm{ml}\right), \mathrm{AGE}-\mathrm{BSA}(800 \mu \mathrm{g} / \mathrm{ml})+\mathrm{LZ}$ $(400 \mu \mathrm{g} / \mathrm{ml})$ or media (DMEM/F12 + 20\% FCS) (Control) or LZ alone (400 $\mu \mathrm{g} / \mathrm{ml})$ for up to $3 \mathrm{~d}$. mRNA expression for PDGF-B, $\alpha 1$ type IV collagen, or tenascin was determined by RT-PCR.

$(17,18)$, indicating that the physiological effects observed are due to AGE-binding of LZ. To avoid its prompt renal elimination, however, we chose to use the full-length lysozyme molecule in these studies.

In support of the potential clinical utility of LZ were the reduction of diabetic level sAGE and the enhanced clearance of urinary AGE. These effects were similar in two models of spontaneous diabetes, type 1 (NOD) and type $2(d b / d b)$, both of which are subject to developing diabetic nephropathy $(31,32)$. These effects also indicated that LZ, if administered in vivo, will maintain its AGE-binding activity even under diabetic conditions.

In a parallel study, pre-loading of normal rats with in vitro made AGE, followed by LZ treatment also led to a reduction of serum AGEs, and a proportional increase in urinary AGE levels. This supported the hypothesis that LZ can function in circulation as a carrier molecule for pre-formed AGE, such as those that are diet derived, and can speed their removal by the kidney. The same study also revealed a significant reduction in rat serum SAGE
A.

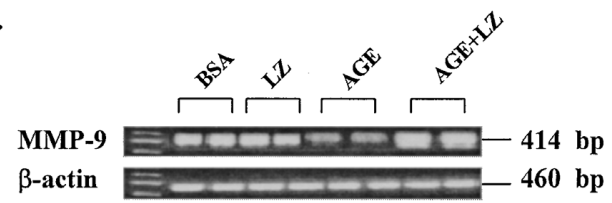

B.

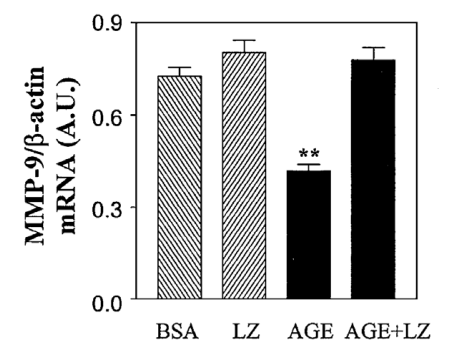

E.

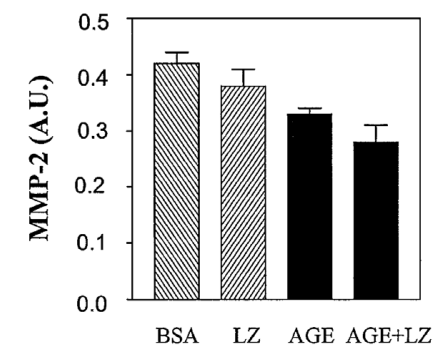

C.

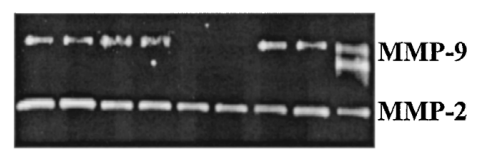

D.

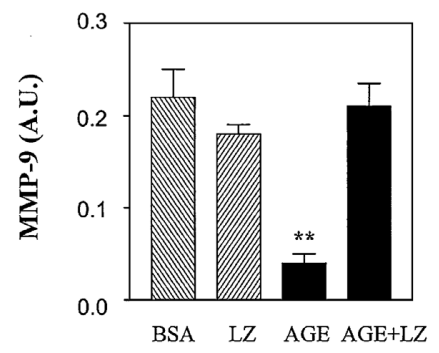

Fig. 5. LZ prevents AGE-suppressible gene expression, and proteolytic activity of mesangial cell MMP-9, but not MMP-2. (A) Primary murine mesangial cell cultures $\left(1 \times 10^{6} /\right.$ well $)$ were incubated with AGE-BSA, BSA $(500 \mu \mathrm{g} / \mathrm{ml}$ each), AGE-BSA + LZ $(200 \mu \mathrm{g} / \mathrm{ml})$ or media (DMEM/ F12 $+20 \%$ FCS) (CL) for $24 \mathrm{hr}$ at $37^{\circ} \mathrm{C}$. RT-PCR for MMP-2 and MMP-9 was performed as described in Methods, $\beta$-actin is shown as an internal control gene. (B) Densitometric analysis of triplicate experiments represented in panel (A). ${ }^{* *}$ p $<0.001$ vs AGE + LZ. (C) MMP-9 and MMP-2 activity in mesangial cell extracts was assessed by zymography, based on gelatinase activity, gels were stained with Coommassie Blue $(0.5 \%)$. From left to right, lanes identities are the same as in (A), in pairs, with the addition of standard (MMP-9, -2). (D,E) Densitometric analysis of three identical experiments on MMP-9 and MMP-2 activities as presented in panel $(\mathbf{C}) .{ }^{* *} \mathrm{p}<0.001$ vs AGE + LZ. 
well below the "normal" range, further confirming that LZ binds equally well to endogenous normally produced AGE.

Relatively little is known about the precise mechanism of renal handling of AGE beyond the fact that AGE clearance correlates with creatinine clearance or glomerular filtration rate (5) and that both the glomerulus and the proximal tubule are involved in AGE turnover and clearance $(33,34)$. LZ has been shown to be readily filtered through the glomerulus and to be taken up in part by the proximal tubule, for proteolytic digestion, mainly by cathepsin-D $(35,36)$ before being excreted into the urine. Thus, the effects of LZ on renal AGE clearance could be explained in part by enhanced filtration of LZ-captured AGE via the glomerulus. There may be a partial AGE re-uptake by the proximal tubule, where the AGE bound to LZ is degraded and AGELZ-peptides are excreted rapidly into the urine. This however remains to be further elucidated.

Interestingly, LZ treatment, however brief, exerted an effect on the progression of albuminuria that was already present in both diabetic mouse models. The LZ effect, exerted against modest degrees of albuminuria in this study, although moderate, was nonetheless suggestive of a potentially novel property of LZ: an ability to effectively abort certain interactions between AGE and renal cells, and/or basement membrane, that would otherwise result in perturbations of permeability and/or selectivity for albumin. This effect was similar in two animal models despite the different types of diabetes and metabolic states. This focuses the action of LZ on glycoxidation derivatives, while keeping them distinct from glucose or insulin actions. While LZ activity could involve the prevention of intracellular reactive oxygen species (ROS) generated by AGE (3, 10,37), this intriguing hypothesis is under investigation. No obvious metabolic nor renal functional parameters, e.g., glycaemia, insulinaemia, creatinine clearance, were influenced by the 2 -week-long LZ treatment; the chronic effects of $\mathrm{LZ}$ remain to be shown, pending the availability of recombinant autologous LZ peptides.

Because of the immunological constraints related to the longer-term in vivo use of a heterologous LZ polypeptide, and in order to expand on the mechanisms of LZ action, our attention turned to relevant cellular systems, namely matrix-producing mesangial cells (MC) and AGE-scavenging macrophages $(9,38,39)$. Both processes appeared enhanced in the presence of LZ, pointing to a potential tool for speedy AGE removal in vivo.

The possibility existed, however, that the LZenhanced AGE uptake might give rise to a more intense AGE-inflammatory response $(9,40)$. On the contrary, LZ effectively and consistently blocked AGE-induced expression of several known inflammatory genes, such as TNF $\alpha$ and IGF-I $(39,40)$. This same effect was also observed when a single, defined glycoxidation species derived from MG and albumin (MG-BSA) was studied. Derivatives of MG have been associated with immune cell activation and oxidant stress induction $(41,42)$. The neutralizing effect of LZ on MG-BSA shown herein strongly supports the specificity of LZ for in-vivo pathogenic AGE derivatives $(7,8,21,41)$ and furthermore it suggests a suppressive effect against cellular oxidative stress.

Additional findings from studies on the developmentally distinct and kidney-specific mesangial cell provided further evidence relevant to the in-vivo utility of LZ, e.g., against diabetic kidney dysfunction. A consistent pattern of suppression of several MC growth and matrix regulatory genes, triggered by AGE $(26,43)$ was exhibited by LZ. A novel finding of note was the reversal by LZ of the AGEspecific suppression of expression and activity of MMP-9. This molecule is an important member of the renal matrix degrading system, and is suppressed in glomerulosclerosis (30,31); no effect was seen on MMP-2, however, by either AGE or LZ. Together, these data indicate that cellular functions, specifically targeted by AGE may include those most responsive to treatment by LZ. The role of LZ in effectively inhibiting mesangial proliferation in the intact diabetic kidney remains an important subject for future studies. On the mechanistic level, it is conceivable that LZ engages reactive carbonylbearing AGE within its hydrophilic ABCD loop, thereby concealing or stabilizing reactive moieties that bear the potential for ROS formation or release $(3,10,37)$. By its cationic nature, the LZ molecule can also form larger complexes with negatively charged AGE-peptides, which are taken up avidly by macrophages. As ROS-generating moieties are rendered inaccessible by LZ, AGE may be processed through the lysosomal system without provoking pro-inflammatory signals. This view may bear a relationship to the neutralizing action of $\mathrm{LZ}$ on potent cellular activators of oxidative stress, such as noted previously with bacterial LPS (44) or viral stimuli (45). The specific molecular pathways remain to be determined; however, preliminary evidence using cultured macrophages over-expressing recombinant LZ, either full-length or as peptides lacking specific domains, e.g., signal peptide or the $A B C D$ domain, indicated that in the absence of the $A B C D$ peptide, the endocytosis-enhancing and cytokine-blocking properties of LZ were ameliorated (46). This may serve as a direct link between the AGE-binding, and the biological effects of LZ reported herein. Furthermore, evidence indicating enhanced LZ expression in mouse diabetic kidney may be consistent with a natural anti-glycoxidative role for this molecule.

The protection noted against local diabetic tissue damage, e.g., atheroma formation, by another AGE-binding peptide, sRAGE was promising (47), however, the ultimate disposal of the RAGE: AGE complex was not addressed in these studies. In the 
present report, the combined evidence of antiinflammatory action in cultured cells and enhanced in vivo AGE elimination provides a reasonable basis for the assertion that LZ is not likely to result in AGE deposition elsewhere nor with "delayed" secondary cellular activation and toxicity.

In conclusion, the host-defense protein lysozyme possesses a unique combination of anti-AGE properties: accelerated cellular AGE turnover, neutralization of pro-inflammatory signals in vitro, and enhanced renal AGE elimination in vivo. These advantages may prove instructive in the design of novel therapies against diabetic complications.

\section{Acknowledgments}

This work was supported in part by an NIH grant (DK57126) and a program project grant from the Juvenile Diabetes Research Foundation (JDRF-41999-697). We thank Ms. Ina Katz for invaluable editorial assistance and Dr. Michael A. Yamin for critically reviewing this manuscript.

\section{References}

1. Baynes JW. (1994) Ageing growth factors; a role in diabetic vascular disease? J. Clin. Invest. 94: 2.

2. Bucala R, Vlassara H, Cerami A. (1992) Advanced glycosylation endproducts. In: Post-translational Modifications of Proteins. J.J. Harding and M.J.C. Crabbe, eds., CRC Press, Inc, Boca Raton, FL., pp: 53-59.

3. Schmidt AM, Yan SD, Wautier J-L, Stern D. (1999) Activation of receptor for advanced glycation endproducts: a mechanism for chronic vascular dysfunction in diabetic vasculopathy and atherosclerosis. Circulation Res. 84: 489-497.

4. Baynes JW. (1991) Role of oxidative stress in development of complications in diabetes. Diabetes 40: 405-412.

5. Makita Z, Bucala R, Rayfield EJ, et al. (1994) Reactive glycosylation endproducts in diabetic uraemia and treatment of renal failure. Lancet 343: 1519-1522.

6. Weiss MF, Ehrhard P, Kader-Attia FA, et al. (2000) Mechanisms for the formation of glycoxidation products in endstage renal disease. Kidney International 57: 2571-2584.

7. Ankrah N-A, Appiah-Opong R. (1999) Toxicity of low levels of methylglyoxal: depletion of blood glutathione and adverse effects on glucose tolerance in mice. Toxicology Letters 109: 61-67.

8. Odani $\mathrm{H}$, Shinzato $\mathrm{T}$, Usami J, et al. (1998) Imidazolium crosslinks derived from reaction of lysine with glyoxal and methylglyoxal are increased in serum proteins of uremic patients: evidence for increased oxidative stress in uremia. FEBS Letters 427: 381-385.

9. Vlassara H, Bucala R, Striker L. (1994) Pathogenic effects of advance glycosylation: biochemical, biologic, and clinical implications for diabetes and aging. Lab. Invest. 70: 138-151.

10. Witko-Sarsat V, Friedlander M, Nguyen Khoa T, et al. (1998) Advanced oxidation protein products as novel mediators of inflammation and monocyte activation in chronic renal failure. J. Immunol. 161: 2524-2532.

11. Brownlee M, Vlassara H, Kooney A, et al. (1986) Aminoguanidine prevents diabetes-induced arterial wall protein crosslinking. Science 232: 1629-1632.

12. Vasan S, Zhang X, Zhang X, et al. (1996) An agent cleaving glucose-derived protein crosslinks in vitro and in vivo. Nature 382: 275-278.

13. Nakamura S, Makita Z, Ishikawa S. (1997) Progression of nephropathy in spontaneous diabetic rats is prevented by OPB-9195, a novel inhibitor of advanced glycation. Diabetes 46: 895-899.
14. He CJ, Li J, Steffes MHM, et al. (1999) Low AGE-diet ameliorates nephropathy in non-obese diabetic (NOD) mice. Diabetes Supplement 1 48: A144.

15. Zheng F, He C, Li J, Vlassara H. (2000) Retriction of AGE content of food, without lowering protein intake prevents diabetic nephropathy (DN) in mice. Diabetes Supplement I 49: Al61.

16. Sava G. (1996) Pharmacological aspects and therapeutic applications of lysozymes. In: Lysozymes: Model Enzymes in Biochemistry and Biology. P. Jolies, ed., Birkhauser Verlag Basel, Switzerland, pp: 433-449.

17. Li YM, Tan AX, Vlassara H. (1995) Antibacterial activity of lysozyme and lactoferrin is inhibited by binding of advanced glycation-modified proteins to a conserved motif. Nat. Med. 1: 1057-1061.

18. Mitsuhashi T, Li YM, Fishbane S, Vlassara H. (1997) Depletion of reactive advanced glycation endproducts from diabetic uremic sera by a lysozyme-linked matrix. J. Clin. Invest. 100: 847-854.

19. Makita Z, Vlassara H, Cerami A, Bucala R. (1992) Immunochemical detection of advanced glycosylation end products in vivo. J. Biol. Chem. 267: 5133-5138.

20. Mitsuhashi T, Vlassara H, Founds H, Li YM. (1997) Standardizing the Immunological easurement of Advanced Glycation Endproducts Using Normal Human Serum. J. Immunol. Methods 207: 79-88.

21. Lo TW, Westwood ME, McLellan AC, et al. (1994) Binding and modification of proteins by methylglyoxal under physiological conditions a kinetic and mechanistic study with $\mathrm{N}$ alpha-acetylarginine, $\mathrm{N}$-alpha-acetylcysteine, and $\mathrm{N}$-alphaacetyllysine, and bovine serum albumin. J. Biol. Chem. 269: 32299-32305.

22. Ahmed MU, Brinkmann Frye E, Degenhardt TP, et al. (1997) ${ }^{\varepsilon} \mathrm{N}$-(Carboxyethyl)lysine, a product of the chemical modification of proteins by methylglyoxal, increases with age in human lens proteins. Biochem. J. 324: 565-570.

23. Li YM, Steffes M, Donnelly T, et al. (1996) Prevention of cardiovascular and renal pathology of aging by the advanced glycation inhibitor aminoguanidine. Proc. Natl. Acad. Sci. USA 93: 3902-3907.

24. He C-J, Zheng F, Sabol J, et al. (2000) Differential expression and function of advanced glycation endproduct (AGE)receptor genes in NOD mouse kidneys; possible role in diabetic and non-diabetic renal disease. Kidney Int. 58: 19311940.

25. Li JJ, Dickson D, Hof PR, et al. (1998) Receptors for advanced glycosylation endproducts in human brain: Role in brain homeostasis. Mol. Med. 4: 46-60.

26. Doi T, Vlassara H, Kirstein $M$, et al. (1992) Receptor-specific increase in extracellular matrix production in mouse mesangial cells by advanced glycosylation end products is mediated via Platelet-Derived Growth Factor. Proc. Natl. Acad. Sci. USA 89: 2873-2877.

27. Skolnick EY, Yang Z, Makita Z, et al. (1991) Human and rat mesangial cell receptors for glucose-modified proteins: potential role in kidney tissue remodelling and diabetic nephropathy. J. Exp. Med. 174: 931-939.

28. Elliot S, Striker L, Hattori M, et al. (1993) Mesangial cells from diabetic NOD mice constitutively secrete increased amounts of insulin-like growth factor-I. Endocr. J. 133: 17831788.

29. Peten EP, Striker L, Garcia-Perez A, et al. (1993) Studies by competitive PCR of glomerulosclerosis in growth hormone transgenic mice. Kidney Int. 43: S55-S58.

30. Lenz O, Eliot SE, Stetler-Stevenson WG. (2000) Matrix metalloproteinases in renal development. J. Am. Soc. Nephrol. 11: 574-581.

31. Jacot TA, Striker GE, Stetler-Stevenson M, et al. (1996) Mesangial cells from transgenic mice with progressive glomerulosclerosis exhibit stable, phenotypic changes including undetectable MMP-9 and increased type IV collagen. Lab. Invest. 75: 791-790.

32. Ziyadeh FN, Hoffman BB, Han DC, et al. (2000) Long-term prevention of renal insufficiency, excess matrix gene expression, 
and glomerular mesangial matrix expansion by treatment with monoclonal-TGF $\beta$ antibody in $\mathrm{db} / \mathrm{db}$ diabetic mice. Proc. Natl. Acad. Sci. USA 97: 8015-8020.

33. Gugliucci A, Bendayan M. (1996) Renal fate of circulating advanced glycation end products (AGE): evidence for reabsorption and catabolism of AGE peptides by renal proximal tubular cells. Diabetologia 39: 149-160.

34. Gugliucci A, Bendayan M. (1995) Reaction of advanced glycation endproducts with renal tissue from normal and streptozotocin-induced diabetic rats: an ultrastructural study using colloidal gold cytochemistry. J. Histochem. Cytochem. 43: 591-600.

35. Haas M, De Zeeuw D, van Zanten A, Meijer DKF. (1993) Quantification of renal low-molecular-weights protein handling in the intact rat. Kidney Int. 43: 949-954.

36. Haas, Kluppel ACA, Wartna ES, et al. (1997) Drug-targeting to the kidney: Renal delivery and degradation of a naproxenlysozyme conjugate in vivo. Kidney Int. 52: 1693-1699.

37. Kislinger T, Fu C, Huber B, et al. (1999) $\varepsilon N$-(Carboxymethyl) lysine adducts of proteins are ligands for receptor for advanced glycation end products that activate cell signaling pathways and modulate gene expression. J. Biol. Chem. 274: 3174031749 .

38. Vlassara H, Brownlee M, Cerami A. (1986) Novel macrophage receptor for glucose-modified proteins is distinct from previously described scavenger receptors. J. Exp. Med. 164: 1301-1309.

39. Vlassara H, Bucala R, Stitt, A. (1998). Vascular complications of diabetes and the role of advanced glycosylation end products. In: An Introduction to Vascular Biology. A. Halliday, et al., eds., Cambridge University Press, UK, pp: 173-194.
40. Vlassara H, Brownlee M, Manogue KR, et al. (1988) Cachectin/tnf and IL-1 induced by glucose-modified proteins: role in normal tissue remodeling. Science 240: 15461548.

41. Thornalley PJ. (1996) Advanced glycation and the development of diabetic complications. Unifying the involvement of glucose, methylglyoxal and oxidative stress. Endocrinol. $\theta$ Metabolism 3: 149-166.

42. Shinohara M, Thornalley PJ, Giardino I, et al. (1998) Overexpression of glyoxalase-I in bovine endothelial cells inhibits intracellular advanced glycation endproduct formation and prevents hyperglycemia-induced increases in macromolecular endocytosis. J. Clin. Invest. 101(5): 1142-1147.

43. Yang CW, Vlassara H, Striker GE, et al. (1995) Administration of AGEs in vivo induces genes implicated in diabetic glomerulosclerosis. Kidney. Int. Suppl. 49: 55-58.

44. Takada K, Ohno N, Yadomae T. (1994) Binding of lysozyme to lipopolysaccharide suppresses-tumor necrosis factor production in vivo. Infection and Immunity 62: 1171-1175.

45. Lee-Huang S, Huang PL, SunY, et al. (1999) Lysozyme and RNAses as anti-HIV components in $\beta$-core preparations of human chorionic gonadotropin. Proc. Natl. Acad. Sci, USA 96: 2678-2681.

46. Chen F, Crandall J, Zhu L, et al. (2000) Overexpression of human recombinant lysozyme (huLZ) by macrophages leads to enhanced glycotoxin uptake and clearance without cell activation: A new model approach for the prevention of diabetic complications. Diabetes Supplement 220: A54.

47. Park LKG, Raman KG, Lee Y, et al. (1998) Suppression of accelerated diabetic atherosclerosis by the soluble receptor for advanced glycation endproducts. Nat. Med. 4: 1025-1031. 